submitted a request to the American Board of Medical Specialties (ABMS) Committee on Certification (COCERT) seeking permission to do so. The American Board of Pediatrics (ABPeds) began issuing certificates without end dates at the beginning of this year, and the American Board of Internal Medicine (ABIM) soon will make a similar request to also begin in 2011. The fact that all 3 primary care Boards have contemplated these changes at the same time is not by mistake. The ABFM, ABPeds, and ABIM have been working together diligently in an effort to harmonize the maintenance of certification programs of each Board for the past 5 years.

James C. Puffer, MD American Board of Family Medicine

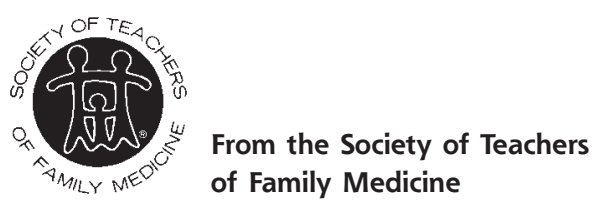

Ann Fam Med 2010;8:468-469. doi:10.1370/afm.1184.

\section{The Evolution of the STFM Foundation- An Improved Synergy Between STFM and the STFM Foundation}

Less than 10 years after the incorporation of the Society of Teachers of Family Medicine (STFM) the STFM Foundation was established primarily to provide the 501c3 tax status necessary for STFM members to make contributions in support of their professional organization. To ensure that the tie to STFM was strong and reciprocal, the membership of the Foundation was defined as the STFM Board of Directors; however, the Foundation Board is a separate group of leaders.

During its infancy, the Foundation's sole fundraising effort was in support of the Leland Blanchard Memorial Lecture. In 1987, during what might be considered its teenage years, the Foundation identified leadership development as its primary focus, recognizing the need for academic family medicine representation at the highest levels of health care administration and policy making. This commitment led to the New Faculty Scholars Program, the Faculty Enhancement Experience Program, the Bishop Fellowship, and the International Scholars Program. One hundred eighty-six STFM members have benefitted from these programs. A brief foray into grant-making in 1992 and 1993 was discontinued due to lack of funding in 1994.

The Foundation may now be seen as in the young adult stage, maturing but with a long life ahead. In fact a good way to think of the Foundation is as timeless, while
STFM is timely. In recent years Foundation Trustees have surveyed STFM members to ascertain the perception of the Foundation's relevance to the STFM member. It was discovered that many STFM members had little knowledge of the Foundation's programs, making the Trustees aware that better communication between the Foundation and STFM members was needed. Many STFM members requested funding for research and projects that fall within the strategic priorities of STFM.

The increasing success of the annual giving campaign enabled the Foundation to respond in 2008 to the request for grant funds by initiating the Group Project Fund. More than $\$ 75,000$ has been awarded for 10 projects, resulting in curricula for adolescent health, e-mail communication, and dietary supplements, in addition to surveys gathering information on domestic violence education, the effect of admission policies on rural service, and factors impacting resident satisfaction.

Also for the first time in 2008, the STFM Board of Directors presented requests to the Foundation for funding of special projects. All requests were approved as submitted. The projects are: the Family Medicine Clerkship Curriculum $(\$ 25,000)$; Center for the History of Family Medicine $(\$ 10,000$ over 5 years); Annals of Family Medicine (\$25,000 for a supplement reporting on the results of the TransforMED demonstration project).

As the Foundation increasingly made financial decisions in response to STFM's strategic priorities, the Trustees scheduled a strategic planning session to align their bylaws and practices with their synergy with STFM. In essence the Foundation's focus changed from working independently of STFM to working collaboratively with STFM. STFM was a partner in this transformation as will be evident in the actions taken since that meeting in November 2009.

Perhaps of greatest significance is the Foundation's new purpose statement, "growing the capacity of STFM to meet its mission and goals." While the Foundation will continue to offer leadership programs, this purpose statement reflects the spirit of harmony between the 2 entities. Changes that have occurred this year are:

- Adding a Foundation Trustee to the STFM Board of Directors (The STFM Board has had a representative on the Foundation Board of Trustees since 2007)

- Sharing of financial statements

- Formalizing the process for the STFM Board to submit proposals to the Foundation

- Revising Foundation bylaws to reflect the new purpose statement

What's next for the Foundation? How do we grow into middle age, defined as providing an optimum level of support for STFM? The success of the Foundation 
directly impacts one of 4 key strategic priorities of STFM, that of financial independence. The long-term sustainability of STFM will be to some degree dependent upon the largesse of STFM members who contribute annually to the Foundation, and who remember STFM in their estate plans. With fewer than $10 \%$ of STFM members being Foundation donors, there is a lot of potential for additional support of leadership programs, research and curriculum development, and special projects. There is also the need to build reserves for operations in times of a slow economy. We know we need to keep moving forward; we know where we are going. If, as this quote says, "You are successful the moment you start moving toward a worthwhile goal," then the STFM Foundation is well on its way.

Peter Coggan, MD, MSEd, STFM Foundation President; Joan Morrill, STFM Foundation Chief Development Officer

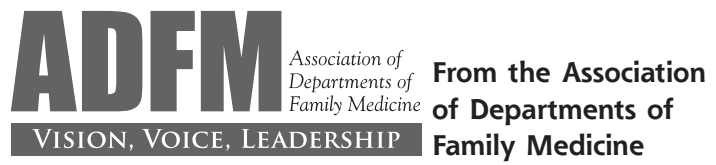

Ann Fam Med 2010;8:469-470. doi:10.1370/afm.1180.

\section{Family Medicine Clerkship, Tracks, and Faculty Support for Family Medicine Education in Departments of Family Medicine: An Update}

Departments of Family Medicine, while experiencing financial resource diminution, are simultaneously called upon to expand their primary care bases and teaching programs, while building and testing medical homes with a goal of advancing to fiscal independence. These rapid changes, while posing unique opportunities, have the potential to diminish and de-prioritize student education as practice transformation occurs.

The changing environment of academic and community clinical venues used for medical student education presents substantial challenges for family medicine educators. Evolving health care reform with greater emphasis on access, quality, outcomes, and appropriate reimbursement are some of the components forcing transformation of family medicine patient care environments to meet emerging primary care delivery challenges. These challenges are being addressed differently across diverse clinical venues potentially creating substantial inconsistency in the way concepts such as the Patient Centered Medical Home are implemented. These evolving primary care delivery settings will likely, create another level of resource inconsis- tency in clinical venues secured and used for family medicine clerkship teaching.

Adding to the challenges of ensuring consistent student teaching experiences in diverse clinical settings is the integration of the national Family Medicine Clerkship Curriculum. The Family Medicine Clerkship Curriculum provides the core portion of student clinical experiences and content that should be provided to students in all clerkship settings across the country, the "what" of family medicine student education. The Curriculum's national task force's decision to start with a small set of content expectations immersed in a patient-centered context may prove to be wise as a second project currently engaged by STFM seeks to determine the "how" as it relates to implementation of the Curriculum. The "how" will likely be complicated by the diversity of the clinical venues where medical students receive their core clinical family medicine training. These settings, which are usually distributed and/or decentralized, make it necessary for curriculum planners to create multiple paths to achieve similar curricular goals (tailoring clinical teaching to unique care delivery settings).

The ADFM's 2010 Quick Hitter Survey of 93 departments (66\% of all ADFM member departments) reveals the presence of a required family medicine Clerkship in $95 \%$ of responding departments with a wide range of resources available to support the clerkship experience. Eighty-four percent of these clerkships were in the 3 rd year with $32 \%$ reporting a 4 -week requirement, $45 \%$ a 6 -week requirement, and $11 \%$ an 8 -week requirement $(9.5 \%$ not mentioning length of time), and 5\% reporting clerkships with both 3rd- and 4th-year students. Multiple unique clerkship arrangements were reported such as 4 th-year requirements, longitudinal experiences, special tracts such as rural locations, special subject interests such as geriatrics, and various levels of integration with other primary care clerkship experiences. These different settings will demand unique implementation strategies to ensure appropriate integration of the new curriculum guidelines.

Efforts to develop consistent curricular core content for the family medicine clerkships will almost certainly require additional departmental investment to support implementation, maintenance, and evolution of these teaching experiences. Many family medicine clerkships are already highly dependent on volunteer teaching and the management of resources beyond the medical school. The dynamic practice transformation occurring in these clinical education sites must be evaluated to determine the implications of these changes on student education. If, especially in academic settings, planned practice transformation 